\title{
THE METHODOLOGICAL APPROACH TO THE MONITORING OF MIGRATION FLOWS FOR THE DEVELOPMENT OF A DIFFERENTIATED TERRITORIAL POLICY
}

\author{
Assoc. Prof. Dr. Irina Vorontsova, \\ Prof. Dr. Boris Khasan, \\ Assoc. Prof. Dr. Larisa Novopashina, \\ Assoc. Prof. Dr. Liudmila Vitkovskaya, \\ Assoc. Prof. Dr. Sergey Krasnousov \\ Siberian Federal University, Russia
}

\begin{abstract}
The article describes the main results of interdisciplinary studies on the development of a methodological approach to monitoring of migration flows in the regions of Siberia and the Arctic zone taking into account current and projected profession composition of settlements, the threshold characteristics of human behavior and institutional mechanisms that ensure the inclusion of monitoring (based on new methodology) in quality of life management system and development of a differentiated spatial policy of the country. The research was supported by the Russian Foundation for Basic Research (RFBR), Project number 15-12-24008. We have taken the step to expand the resource capabilities of the economists through the research tools of social psychologists.
\end{abstract}

Keywords: territorial policy, the quality of life, migratory behavior, well-being.

\section{INTRODUCTION}

The current structure of today migratory outflow and inflow is not able to ensure the implementation as the current economic activities and investment projects in most of the regions of Siberia and the Arctic zone. The Krasnoyarsk Krai is served as a model region in the study. $40 \%$ of its territory is a resource-rich Arctic area, and the fourth technological way (average 85.23\%) dominates at the economy Changes in the structure of the employed people of the Krasnoyarsk Krai as a typical region of Siberia are provided by agriculture and manufacturing and are due mainly to the decline in production of these areas, rather than productivity growth. [4]

Around $35 \%$ of unemployed of the regional center (the city of Krasnoyarsk) are citizens who have professional education (bachelors and masters). However, the most popular are working professions with low qualification last 5 years. The intensity of the outflow of skilled personnel, especially young people, grows despite the high objective indicators of living standards. The Krasnoyarsk Krai is the leader among regions of the Siberian Federal District on the Human development index due to the high, compared with the national average, indices of income and education (in 2013 it was 14th place in the ranking of Russian and 2nd among the Siberian Federal District). In 2015-2016 Krasnoyarsk Krai more than any other Siberian regions lost population due to migration disposal to other Siberian regions, primarily to the Novosibirsk Oblast. [11] 
Thus, the key factor of new immigration policy is quality of life in the aspect of population groups. The category of "quality of life" includes not only the objective factors (quality of air or water, the availability of cultural institutions, for example), and subjective (eg, life satisfaction of individuals, ready for a tactical or strategic forms of behavior associated with the migration capability), must be complemented such a characteristic as the profession composition of the settlement. The quality of life reflects the specificity of the claims of the various groups of the population to various aspects of the socio-economic conditions.

Consequently, the decision regarding formation of favorable for the innovation economy regional policy, focused on quality of life, need to be differentiated, affect the interests not of the "average citizen", but the key active groups. Just uniqueness of claims of the active groups of the population to ensure conditions for the realization of research and business activity leads to the formation of the complexity of the socioeconomic living conditions. In the current paradigm of territorial policy life conditions are formed in accordance with the standards, without taking into account the specifics of the claims of groups willing to invest their abilities in the region's economy.

The main objective of the study is to develop a methodological assessment tool of wellbeing of the population and the prediction of active and passive migration behavior on the basis of threshold values for formation of differentiated territorial policy.

\section{MATERIALS AND METHODS}

Approaches to modeling and evaluation of the quality can be divided into objective (R. Bauer [3], S.A. Aivazian [2], N.V. Zubarevich [13]), subjective (A. Campbell \& Ph. Converse [5], F. M.Andrews \& S. B. Withey [1], G.M. Zarakovskiy [12], World Health Organization methodology [9]) and integral (Ed. Diener \& Suh. Eunkook [6], I.V. Grishina [7]). The approach to assessing the quality of life on the basis of objective indicators allows to make a comparative analysis of the quality of life of the population of Siberian regions, as there is an official statistics according to groups of indicators, with less complexity of the study, compared with social methods. However, they do not signal the "thresholds" of behavior due to the lack of evidence-based recommendations on the results of the study "threshold values" of behavior of the population and labor force, leading to their outflow, inflow and "anchoring" in the territory. As a result, migration flows control based on the traditional approach to assessing the quality of life are unbalanced.

To adopt balanced policy-making decisions it requires information that allows not only to fix the features of migratory behavior, the circumstances of decisions about displacement or participating in protest actions taken by key population groups, but more important in the spatial aspect of the policy is to predict the migratory behavior.

Traditional sociology has enough tools to fix the social situation, but not enough for its prediction [10]. The question "What are the characteristics and their thresholds for human decision making about the change of place of business and residence?" remains unanswered. Therefore, we have initiated an interdisciplinary study on the construction of a unique research tool of social reality. As a result, we have developed a research model of well-being reflecting the motivation of human behavior and the choice of strategies on the basis of constructive psychology of conflict. 
Schematic diagram of the model can be reflected in the form of a system of ideas of population about the external life factors (state of health care, education, housing, access to social services, the level of socio-economic development and the state of the labor market, environment) and internal life factors (civil, existential, professional, consumer position and employment). Internal factors inherent balance characteristics.. They include various aspects of life equally distributed among all individuals. For example, a productive factor for all individuals is identified with the components: labor, creation and education. Accordingly, each person has own understanding of the factors and relation to each aspect. We suggest if these factors can be determined by set of several parameters, so they can be measured. To do this we use the concept of relative deprivation. Thus, we express the deprivation with factors of subjective well-being as the difference between the actual and expected level of this factors. Dissatisfaction induced by deprivation stimulates migration of any kind [8]. By questioning, we can clarify the details for each factor, determine the priorities and the border zone, the intersection of which will contribute to the rapid migration. For "now" we determine the levels of deprivation or borderline indicators, in which there is frustration. For "future" there is the possibility of determining the boundaries at which the migration will occur. Hypothetically, the individual migration can occur if the difference between potential and the current level is less than a certain value. That is, during the subjective assessment of well-being is important to take into account the lower threshold characteristics, expressed in everyday language as "I can't go on living in such conditions". Clarification of this value is the possible by using a questionnaire. Currently, only the upper threshold characteristics are in the field of research, which in the ordinary language of the question is "how do you want to live?", but one can't keep up with expectations. It is obvious that the value scales will vary not only from one individual to another, but even a single respondent. We have no yet tools to numerically express the values of the scales that would undoubtedly help not only in our study, but also in social psychology in general, so their values remains in the respondent's mind, and even there may not be a numerical expression. Presumably, factor of existentiality is that the measurement scale, which the respondent uses. Thus, for example, the respondent may perceive the scale as set of objects, factors and living conditions, the presence of certain people, or the absence of any of the presented aspects on the contrary. That is, the respondent is required to visualize the representation and understanding of quality of life factors and his potential in these factors.

A graphical representation of well-being factors reflected on the scales that do not have numerical values, but have their high and low, and based on the state of personalized well-being of individual respondents. If we combine the zero point of the four scales, we get something similar to the chart with the axes of $x$ and $y$, but they have no negative values. Each of the four sides has nothing to do with the other three, except the reference point. Order of scales does not matter, because count for each scale is independent of reference for others. In such model we can be clearly noted the growth potential in a variety of well-being factors expected by respondent in according to his personalized experiences. If, for example, two figures intersect, it means that respondents indicate a negative development potential at least for one factor of the quality of life. Lack of numerical expression does not stop to note the positive or negative trends. 
To determine the threshold values of quality of life factors, we performed a series of experiments using a research model well-being assessment: a series of focus groups with migrants from the Krasnoyarsk Krai in St. Petersburg; a series of focus groups with residents of the Krasnoyarsk Krai; a questionnaire on the subject of clarification of basic well-being thresholds to measure, based on Google Forms service. More than 17 thousand people took part under the terms of voluntary and anonymous. Our study was designed to test a well-being model. The semantic differential modification was used as a measuring scale.

\section{RESULTS}

The state of well-being of young professionals under the age of 30 years, who left the Krasnoyarsk Krai (Figure 1), characterized by accentuation of productive component, they do not see any possibility of professional realization on the territory of the region. Their existential focus of life in the region tends to zero, that led them to a real move from Siberia. However, the consumer focus takes them more opportunities in the region, but living in another city does not cause existential stress, as shown by the red line in Fig. 1.

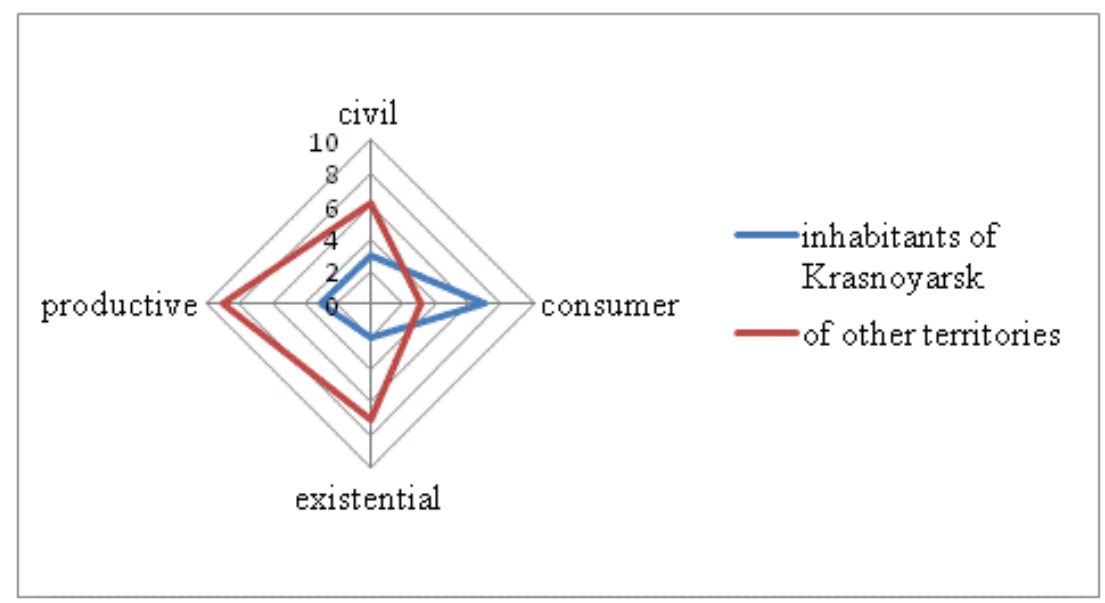

Figure 1 - Profile of well-being of professionals up to 30 years

Well-being of professionals aged 45 years and older living in the Krasnoyarsk Krai reflects another situation (Figure 2).

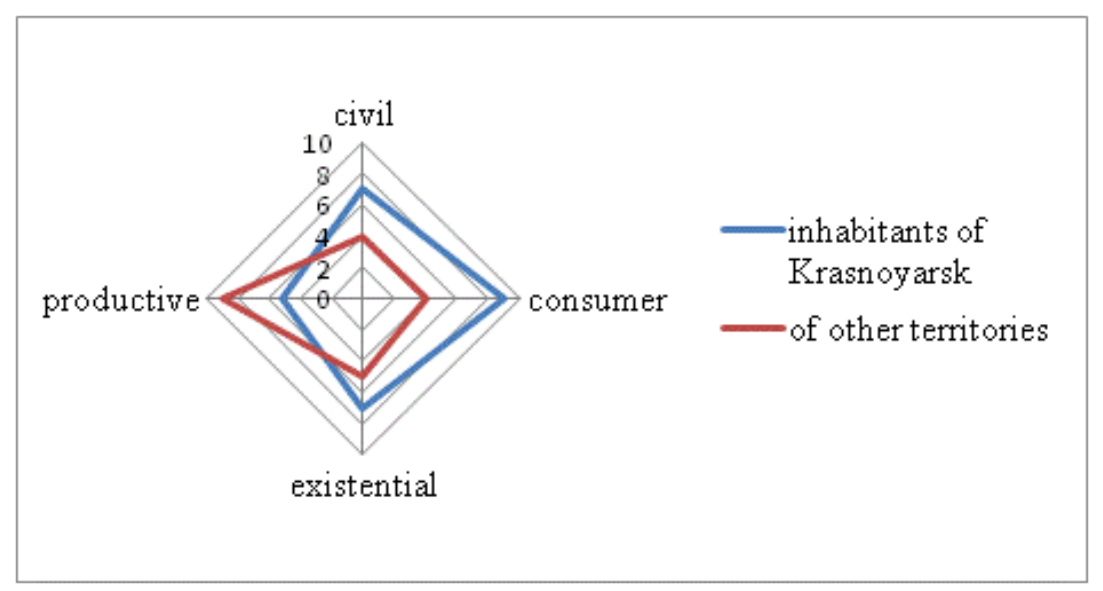

Figure 2 - Profile of well-being of professionals over 45 years 
They too do not see any sufficient capacity in the implementation of profession and employment (red line) and too the consumer focus is maximal expressed in relation to stay in the Krasnoyarsk Krai (blue line), but other focuses on living in the region do not cause deprivation. The existential focus on living in the territory of the region is expressed more clearly in contrast to the residence in another territory and, accordingly, there is no push to move.

One of the main focuses of the survey was the question "How do you feel your appropriation in the territory (the area in which you live)?". More than a third of respondents believe the region and the city are own home, and probably in the future home of their children (Figure 3). 6\% of respondents felt the strength to change the capabilities of the territory. $13 \%$ of respondents indicate that the importance of what they are doing is higher than the importance of the place where they are. This is probably due to the fact that productive focus of the subjective well-being is more important, thanks to which these respondents realize their life goals. We also suppose that, presumably, respondents who believe that the importance of the employment is above the importance of their residence, will likely be prone to existential, internal migration if they can't improve subjective well-being by any factor.

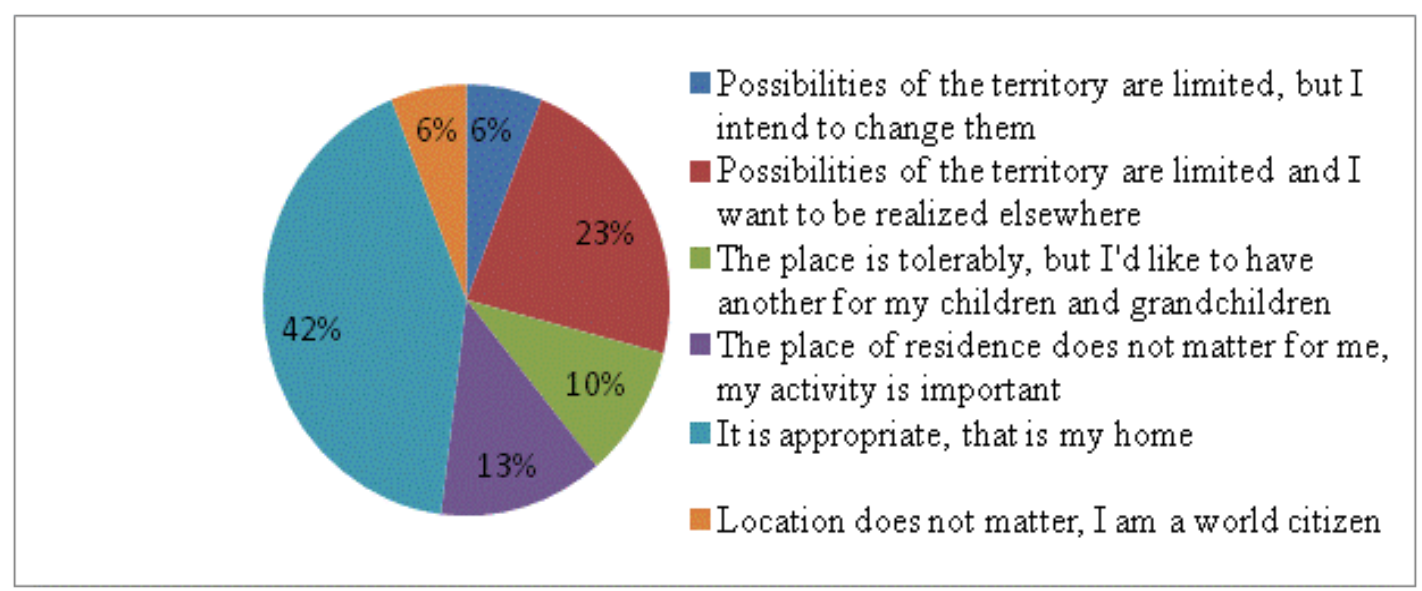

Figure 3 - Evaluation of the respondents of their appropriation in that territory

To test our hypothesis, we pay attention only to the answers "Possibilities of the territory are limited, but I intend to change them", "The place is tolerably, but I'd like to have another for my children and grandchildren", "It is appropriate, this is my home," because these options mean that people stay within the region in the near future and their subjective sense of the impossibility of contribution to living focuses is expected to be expressed in the "avoid", i.e. internal, existential migration. Distribution of answers to the question "It is important for me, but I do not see any possibility to achieve it" is in Table 1.

Table 1 - Distribution of answers on the main issues of the questionnaire, expressing a subjective state of well-being of the consumer focus of life.

\begin{tabular}{lc}
\hline Well-being focuses & $\begin{array}{c}\text { Distribution of answers to the question "It is important for me, } \\
\text { but I do not see any possibility to achieve it", } \%\end{array}$ \\
\hline Civil focus & 24.51 \\
\hline Productive focus & 11.46 \\
\hline Consumer focus & 14.30 \\
\hline Existential focus & 15.03 \\
\hline
\end{tabular}




\section{DISCUSSION}

On the basis of the results of the study it can be argued that, in general, dissatisfaction in the three focuses is reflected in dissatisfaction on the existential focus. It clearly shows the impact on the subjective well-being as a whole, as this aspect is responsible for overall human existence, while dissatisfaction on other focuses shows representations, that more likely determine the decision of internal migration.

In connection with these provisions, it is important to pay attention to the three options of migratory behavior: dropping out of the territory; disposal of the profession to another (for example, teachers to retailers or engineers to taxi drivers); internal migration - the refusal of the realization of their own potential (professional capitalization) and "avoid" the active position to addiction or surrogate forms of activity (pyramids, sectarian preaching). In other words, the problem is not only in attracting and retaining people in the territory, but also in the choice of the vector of human social activity. That is, either capitalization or compensation or protective behavior avoidance of social and productive activity.

Withal, a profession currently serves most institutionalized variant of human social activity, to a large extent, determines the other activities. Hence, extrapolating the experience of well-being as human capital, which determines the options for social mobility and its thresholds is of high probability.

The developed model adequately covers all aspects of life of individuals. The questionnaire-based model can qualitatively determine self-perception, well-being of respondents at various focuses and select locations (aspects of focuses) in which there is a certain "tension" or prerequisites for that. As a result of testing we identify possible further development with the subsequent use in a large-scale studies on the subjective well-being of people in various areas.

According to the survey we marked high levels of subjective well-being for all focuses and, at the same time, the majority of respondents noted that territory as appropriate for living themselves and their children in the future. Expectations of subjectively sufficient level of development in relations, creativity, various activities, as well as a feeling of sufficient security contribute to the continuation of the respondents living in this city or this region in the long term at least 5-7 years. Such high subjective well-being indicators should also say that internal migration, which in our study is more important than external, rather unlikely. To be able to identify "internal migrants" more accurately requires further development of the model, which takes into account the impact of subjective "tension" on the well-being in general.

We received pilot data that are needed at this stage to work out a mechanism for monitoring.

\section{CONCLUSION}

The results of testing of the population well-being model demonstrate the ability to analyze the growth potential in various factors of subjective well-being of population groups.

This is the first trial operation of the model, which shows the future and perhaps the direction of its further development, which, in our opinion, is important, because field of study of subjective well-being still does not contain so much research, especially 
aimed at the internal aspects. The importance of taking into account the state of wellbeing of the population in the process of spatial development policy cannot be overestimated. It will minimize the negative effects of the contradiction between the real driver of migration activity and territorial policy aimed at improving the quality of life of the population. Failure to understand this fact by the authorities provokes increase of the protest behavior of the population (active and passive migration, drug addiction, alcoholism - the relevance of these problems for the Arctic territories of Siberia in recent years has increased).

The results of our study show that to reduce the adverse effects of migration on the territory of the Siberian regions is possible through the development of forms and methods of professionalization (adaptation of the profession) of young professionals primarily in the areas of education, health and culture.

\section{REFERENCES}

[1] Andrews F. M., \& Withey S. B. Social Indicators of Well-being: Americans' Perceptions of Life Quality, New York, Plenum Press, USA,1976. DOI:10.1007/978-14684-2253-5.

[2] Aivazian S. A. Synthetic Indicators of Quality of Life: Construction and Utilization for Social-Economic Management and Comparative Analysis, Austrian Journal of Statistics, Austria, vol.34/ issue 2, pp 69-77, 2005.

[3] Bauer R.A. Social Indicators. Cambridge, Massachusetts: MIT Press, USA, 1966.

[4] Bukharova E.B., Samusenko S.A., Semenova A.R. Integrated Assessment of Economic Security in a Resource Region, Region: Economics and Sociology, Russia, vol. 4, pp 113-138, 2016. DOI: 10.15372/REG20160405.

[5] Campbell A., Converse Ph., Russell W. The Quality of American Life: Perceptions, Evaluations and Satisfactions, Sage Foundation, USA, 1979.

[6] Diener Ed. \& Eunkook Suh. Measuring quality of life: Economic, Social, and Subjective Indicators, Social Indicators Research. An International and Interdisciplinary Journal for Quality-of-Life Measurement, vol. 40, pp 189-216, 1997. DOI:10.1023/A:1006859511756.

[7] Grishina I. V., Polynev A. O., Timonin S. A. Quality of Life of the Population of Regions of Russia: Methodology of Research and Results of a Complex Assessment[Kachestvo zhizni naseleniia regionov Rossii: metodologiia issledovaniia I resul'taty kompleksnoi otsenki]. Modern Productive Forces, Russia, vol.1, pp 70-83, 2012.

[8] Khasan B.I., Novopashina L.A. Conflict Situation and Its Manifestation in Assessment of Quality of Life, Journal of Siberian Federal University. Humanities \& Social Sciences, Russia, vol. 4/ issue 7, pp 597-608, 2014.

[9] Skevington S.M., Lotfy M., O’Connell K.A. The World Health Organization's WHOQOL-BREF Quality of Life Assessment: Psychometric Properties and Results of the International Field Trial. A Report from the WHOQOL Group - Quality of Life Research, Kluwer Academic Publishers, Printed in the Netherlands, vol.13/issue 2, pp 299-310, 2004. DOI: 10.1023/B:QURE.0000018486.91360.00 
[10] Urry John Sociology Beyond Societies: Mobilities for the Twenty-first CenturyPsychology Press, London and New York, 2000.

[11] Vorontsova, Irina P.; Vitkovskaya, Liudmila K. Investing into Siberian Human Potential Development: Investment into "Export" Professionals or Growth of Local Human Capital Assets? Journal of Siberian Federal University. Humanities \& Social Sciences, Russia, vol. 9/issue 11, pp 2697-2705, 2016. DOI: 10.17516/1997-1370-20169-11-2697-2705.

[12] Zarakovskii G.M. Quality of Life of the Population of Russia: Psychological Components [Kachestvo zhizni naseleniia Rossii: psikhologicheskie sostavliaushchie]. Moscow, Sense, Russia, 2009.

[13] Zubarevich N. V. Four Russias: Human Potential and Social Differentiation of Russian Regions and Cities. In: Russia 2025: Scenarios for the Russian Future. Edited by M. Lipman and N. Petrov. Palgrave Macmillan Ltd United Kingdom, 2013. 